\title{
Cultural Variability in Web Content: A Comparative Analysis of American and Turkish Websites
}

\author{
Gaye Karaçay-Aydın \\ Department of Management, Boğaziçi University \\ 34342 Bebek-İstanbul-Turkey \\ Tel: 90-532-456-9442Ｅ-mail: gaye.karacay@boun.edu.tr \\ Elif Akben-Selçuk \\ Department of Management, Boğaziçi University \\ 34342 Bebek-İstanbul-Turkey \\ Tel: 90-532-602-2226 E-mail: elif.akben@boun.edu.tr \\ Aslı Elif Aydın-Altınoklar \\ Department of Management, Istanbul Bilgi University \\ 34060 Eyüp-İstanbul-Turkey \\ Tel: 90-533-466-8229 E-mail: aeaydin@bilgi.edu.tr
}

\begin{abstract}
The objective of this article is to investigate the extent of differentiation of web communication on cultural grounds. For this purpose, US based Fortune 500 companies' domestic websites and their Turkish counterparts were culturally examined. Through a content analysis, the reflections of Hofstede's (1980) and Hall's (1976) cultural dimensions on the website content of the selected 88 websites were investigated. In general, significant differences were found in the depiction of cultural values on the websites examined. The results of this study provide implications for global companies in their attempts to culturally adapt their websites to local markets, in particular to Turkey.
\end{abstract}

Keywords: Website content, Cultural adaptation, Cultural dimensions, Turkey, USA

\section{Introduction}

During recent decades, internet has become increasingly important for companies that carried their operations to web base. The prospects of connecting with a vast number of consumers throughout the world at comparably lower costs enhanced the attractiveness of internet. The rise of the internet as a globally accessible communication medium presents new challenges for multinational companies given that they may need to adjust their communication tools based on cultural differences. Especially in web communication, attuning to local climate is necessary to enhance the impact of on line sources. In this respect, cultural adaptation has become a vital strategy for companies that desire to succeed beyond borders.

The purpose of this study is to investigate the ways web communication differentiates on cultural grounds and to explore how companies reach local customers. In particular, using Hofstede's (1980) and Hall's (1970) cultural dimensions, the extent of adaptation on US and Turkish company websites will be investigated.

The remainder of the article is organized as follows. The next section reviews the literature on cultural models. Then, the framework for examining website content is developed. Following that, the statistical analysis conducted for this study is explained in detail. Finally, the findings of the study are disclosed and concluding remarks are made with managerial implications.

\section{Theroretical background}

Culture has always been a vital element for the study of international businesses (Kabasakal et al., 2006). In the literature, several theorists have proposed that cultures vary along different dimensions. Among them, Hofstede's (1980/1984) and Hall's (1976/1981) cultural typologies have been extensively used in cultural studies.

According to Hofstede (1980), national cultures differ along four main criteria which are power distance, uncertainty avoidance, masculinity-femininity and individualism-collectivism. Among these dimensions, power distance indicates 
the extent to which a society accepts the fact that power in institutions and organizations is distributed unequally. Uncertainty avoidance dimension indicates the extent to which society feels threatened by uncertain situations and tries to avoid them. While masculine values emphasize assertiveness and acquisition of money, feminine values are on the opposite side of the continuum. Individualist societies like Western societies emphasize individual initiative and prestige, whereas collectivistic societies like Eastern societies value communal well-being and harmony.

In his study, Hofstede (1980) depicted the cultural maps of the world by using data from 40 countries. From his work, one can find out the relative position of these 40 countries on the four dimensions. According to these maps, while Unites States rates relatively low in power distance and uncertainty avoidance dimensions, it rates high in individualism and masculinity dimensions. On the other hand, Turkey rates high in power distance, uncertainty avoidance, collectivism dimensions as well as relatively high in feminine dimension.

On the other hand, Hall (1976) proposed that cultures also differ in the extent to which contextual information is important for effective and satisfying communication. Hall (1976) categorized cultures as high- and low-context based on dimensions of communication and understanding.

According to Hall (1976), in high-context cultures communication is comprised of simple messages with deep meaning. High-context communication tends to be more indirect and more formal. While high-context communication is fast, efficient, and satisfying, time must be devoted to the formulation of the language to be high-context. The tendency in high context cultures is to provide less information in the verbal part of the message. This is in line with the generally accepted rule that what is not being said can carry more meaning than what is being said. In contrast, low-context cultures value facts and directness. Communication is expected to be straightforward, concise, and efficient in describing what action is expected. In low-context cultures, detailed and comprehensive information is vested in the message with explicit words and sentences.

In high-context, typically Eastern cultures, communication depends on the external environment, situational factors, and non-verbal behaviour. Message meanings are derived primarily from context. In contrast, in low-context, typically Western cultures, the meaning of a given communication comes directly through verbal channels. Hall (1976) pointed out that although no culture exists exclusively at either end of the scale, some cultures can be classified as high while others are considered low. In line with Hall's study (1976) examples of high-context communications can be found in Turkish culture while examples of low-context communications can be found in American culture.

In this study, we expect to observe the manifestation of the specific cultural characteristics of Turkish and American cultures in the selected company websites. In particular, we expect to see US websites to reflect more individualistic, masculine, low-context cultural characteristics; while their adapted Turkish counterparts reflect more power distance, uncertainty avoidance, collectivist, feminine and high-context cultural features.

\section{Framework for Analysis}

In this study Hofstede's (1980) and Hall's (1976) cultural dimensions were used to construct the basis of a comparative analysis. In order to be able to compare the web site content of US and Turkish companies, the first step was to establish website features representing the cultural typologies. Therefore, a review of literature was made with a focus on studies investigating reflections of cultural typologies in communication domain (Cheng and Schewitzer, 1996; Ju-Pak, 1999; Singh et al., 2003; Zhao et al., 2003; Okazaki, 2004). Based on this review, a wide range of website features, which have qualities corresponding to the cultural traits, were determined. Secondly, a focus group study was conducted among six graduate students in order to explore website attributes and applications of cultural traits. As a result, a number of website features were specified. Next, the authors judged generality and measurability of these features. Using a random sample of US company websites and their Turkish counterparts, the operationalization of cultural traits was tested. It was seen that the items representing power distance dimension of Hofstede (1980) such as company organization charts, employee titles and information about the CEO, weren't found in any of Turkish websites. Thus, this dimension was excluded from the analysis. Apart from that, some of the items were removed since they overlapped with others in order to achieve parsimony. As a result, a list of fourteen web features representing Hofstede's three cultural dimensions and Hall's context dimension in web communication was developed. These are provided in Table 1. A description of the cultural dimensions and of the operational categories is provided below.

Uncertainty Avoidance: High uncertainty avoidance cultures tend to avoid ambivalent circumstances (Hofstede, 1980); they tend to seek for as much information as possible in order to reduce unpredictability. Therefore, we expect that the presence of site maps and search tools will be common in Turkish websites. Parallel to that, we expect Turkish websites to present a thorough company history in order to build a trustworthy image. Moreover, high uncertainty avoidance societies are generally risk averse and approach innovations and novelties with scepticism. For that reason, we anticipate Turkish websites to accentuate conventional aspects of company and product whereas US websites to emphasize the way company explores new frontiers. 
Individualism - Collectivism: Collectivist societies value togetherness (Holfstede, 1980) hence family/group themes and pictures are expected to be more prevalent than individual themes and pictures in Turkish websites. Additionally we expect that the content in Turkish websites, especially in the home page, will employ a group style by using pronouns such as we, our, us instead of indirect sentence structures or pronouns such as I, me, you in order to reflect a sense of family within the company. Finally, we believe that there will be more announcements of events and activities in Turkish websites, which will convey the importance of community relations for the companies. However, such announcements will be less common in US websites

Masculinity - Femininity: Masculine cultures stress the importance of performance outcomes, determination and success (Hofstede, 1980). Consequently we anticipate more financial information such as stock prices, annual reports etc. to be present on US websites. Similarly, in US websites we expect more statements related to success of the company such as company and product awards, accreditations from prominent institutions. Another essential aspect of masculine societies is to emphasize distinguished gender roles and assign certain duties among men and women strictly (Hofstede, 1991). Accordingly we deduce that a more rigid distinction will be discernable in the pictures of US websites compared to the Turkish ones.

High - Low Context: In high context communication, the meaning is disclosed in the context whereas in low context communication the meaning is revealed directly in the message (Zhao et al., 2003). Consequently we expect higher proportion of pictures and limited amount of information especially in product pages of Turkish websites. On the contrary lower proportion of pictures and more detailed information will be presented in US websites. An additional characteristic of high context societies is to place more emphasis on non-verbal aspects of communication compared to low context societies (Hall 1976). Therefore, we predict more animation, films and music in Turkish websites. Moreover, high context societies prefer an indirect form of communication, with several layers of meaning (Hall, 1976). Thus we believe information will be more layered and hidden with multiple sidebars in Turkish websites, while it will be more direct and accessible in US websites beneath a single sidebar.

\section{Methodology}

This study used content analysis as the research method. Content analysis is "a research technique for the objective, systematic, and quantitative description of the manifest content of communication" (Berelson, 1958, p.18). The objective feature of content analysis implies that there should be agreement among different analysts. Systematic description suggests that the researcher uses generally recognized randomization procedures and predetermined criteria to select items for analysis. Finally, the quantitative feature of content analysis ensures precision in measurement and enables the researcher to apply statistical tests (Cobb-Walgren and Mohr, 1998).

In this study, we used content analysis to investigate cultural values depicted on Turkish and US websites. More specifically, the unit of analysis was the US and Turkish websites of selected companies. These websites were analyzed for the presence or absence of the fourteen predefined criteria by coding " 1 " or " 0 ".

\subsection{Sample selection}

The sample for the study was generated from the list of US based Fortune 500 companies. Of these 500 companies, the ones with a country specific website for Turkey were selected. For some companies, the homepage was in Turkish but the rest of the site was in English, so these companies were eliminated. As a result, a total of 44 companies and thus 88 websites were retained for analysis.

\subsection{Reliability}

Three coders independently analyzed the 88 websites for the predetermined fourteen dimensions. In total, this resulted in 1232 (88x14) codings. In case of disagreement among judges, a majority rule was used to determine the final coding. To assess the psychometric soundness of the analysis, the agreement among all three judges was checked, which provided a stringent confirmation of reliability. The three coders agreed on 821 of the items, hence the percentage inter-judge agreement was 67 percent.

However, the percentage agreement is not a satisfactory measure since part of agreement might be due to luck. Therefore, statistical z-test was conducted (Zimmer and Golden, 1988). First, the probability by chance alone that the three judges will assign the same coding was calculated to be 0.25 . Then, a z-score was calculated according to the following standard formula.

$$
z=\frac{k-E k}{\sqrt{n p(1-p)}}
$$

where,

$k=821$ (actual number of matches), $E k=616$ (expected number of matches), $N=1232$ (total number of codings) and $p=0.25$ (probability that three coders will agree by chance alone). The z-score calculated according to the above formula was 13.49 , which is statistically different from zero at a $99 \%$ confidence level. 
As a final measure of reliability, the Holsti (1969) value was calculated according to the following formula

$H=\frac{n A}{1+(n-1) A}$

where,

$n=3$ (number of judges) and $A=0.67$ (average agreement). The result of the above formula was 0.86 for our sample. Since it is above the 0.85 threshold value, the reliability is satisfactory.

\section{Analysis and Findings}

First, the frequencies of the fourteen cultural value dimensions were compared by a one-way analysis of variance. As can be seen on Table 2, the presence of ten of these fourteen dimensions differed significantly between US and Turkish websites.

As anticipated, the percentage of occurrence of family or group theme and "we" approach was more common on Turkish websites than on US websites. Also, annual reports and success stories were more frequent on US websites. Finally, Turkish websites displayed more pictures, less detailed information, and more sidebars compared to US websites.

Contrary to our expectations, however, US websites displayed more features related to uncertainty avoidance, namely, the presence of a site map, company history and tradition theme. This might be due to the fact that US companies consider Turkish websites as auxiliary divisions, and do not bother to translate all the available information from English to Turkish.

Second, the overall scores for each of the four dimensions were calculated in the following way. The average presence of each of the subcategories within each dimension was calculated and was recorded as an aggregate score for that dimension. For instance, the aggregate score for the individualism-collectivism dimension was calculated by counting the presence of all three subcategories on a website, and then dividing the number by three. Then, a one-way analysis of variance was implemented and the results are shown on Table 3. As anticipated, Turkish websites displayed more collectivist features than US websites. Second, Turkish websites depicted lower masculine values. Third, Turkish websites displayed more high context oriented features. Finally, contrary to our expectations, US websites demonstrated more uncertainty avoidance features compared to Turkish websites. For all these four dimensions, the differences were statistically significant.

Third, a cluster analysis was performed to investigate whether these 88 websites would be divided in two groups (Turkish and US websites) based on cultural dimensions as we expected. In applying cluster analysis, we followed the approach of employing hierarchical and non-hierarchical methods in combination. The first step was hierarchical clustering to determine the appropriate number of clusters. We used the agglomerative technique and chose Ward's (1963) method, which maximizes between sample variation and minimizes within sample variation. Hierarchical cluster analysis pointed to a two cluster solution. In the second step, we used k-means clustering to further improve the cluster solution and to see whether the clusters are statistically stable. K-means cluster analysis resulted in two clusters containing 42 and 46 websites each. When we checked each website for cluster membership, it was seen that the first cluster consisted of 41 US and 1 Turkish websites. The second cluster, on the other hand, was comprised of 43 Turkish and 3 US websites. Thus, cultural value dimensions approximately grouped the Turkish and US websites into two clusters. Finally, as can be seen on Table 4, nine of the fourteen dimensions significantly differed across the two clusters.

\section{Conclusions and Implications}

The evidence presented in the content analysis of 88 US and Turkish websites showed that the web is not a culturally neutral medium, but it reflects the cultural environment that surrounds the consumers. The analysis indicated that US websites differ from their Turkish counterparts in a variety of ways, mainly in line with the cultural dimensions of Hofstede (1980) and Hall (1976).

In general, it was seen from the analyzed websites that US based international companies employ some effort to their localization strategies on the Web for their Turkish websites. In line with the main propositions of the study, Turkish websites display more collectivist and more high-context oriented features than US websites while they show lower masculine values. However, contrary to our expectations, US websites display more features related to uncertainty avoidance.

We believe that the situation with high uncertainty avoidance applications of US websites is due to the tendency of the selected companies to consider Turkish websites as auxiliary divisions, and not to invest necessary time and effort to translate all the available information from English to Turkish. However, as a culture having a high uncertainty avoidance tendency, Turkish consumers may look for applications on web that incorporate hands down approach. This 
may increase Turkish consumers' trust on the web service of the related companies as well as their e-commerce applications.

Although the results of this study may not be generalized due to the limited number of country specific web page comparisons, they have some implications for international companies with domestic and international web pages, as well as marketers and web designers in their website localization efforts.

As pointed out by Barber and Badre (1998), Fock (2000) and Simon (1999), country-specific and culturally reflective web pages increase website usability and interactivity. This is mostly due to the fact that web pages that have a local feel provide an ease for local consumers while integrating with web (Barber and Badre, 1998).

In an era where communication has been shifted to internet base, multinational companies have also chosen this effective medium for their advertising and communication applications. Cultural adaptation on the web is important for the international companies to be accepted and trusted by the local customers. By incorporating the features of local culture in to their country specific websites, international companies may help consumers to feel familiar while using their web pages. We believe that by paying attention to the cultural adaptation of web pages, international companies, marketers and web designers may help to the web-based promotion of international companies while reaching more consumers without losing personal touch.

\section{References}

Barber, W. \& Badre, A. (1998). Culturability: The Merging of Culture and Usability. Proceedings of the $4^{\text {th }}$ Conference on Human Factors and the Web, [online] Available: http://zing.ncsl.nist.gov/hfweb/att4/proceedings/barber/ (October 21, 2009).

Berelson, B. (1952). Content Analysis in Communication Research. New York, NY: Free Press.

Cheng, H., \& Schweitzer, J. C. (1996). Cultural Values Reflected in Chinese and U.S. TV Advertising. Journal of Advertising Research, 3, 27-45.

Cobb-Walgren, C. J. \& Mohr, L. A. (1998). Symbols in Service Advertisements. Journal of Services Marketing, 12(2), 129-151.

Fock, H. (2000). Cultural influences on marketing communication on the World Wide Web. Paper Presented at the Multicultural Marketing Conference, Hong Kong.

Hall, E. T. (1976/1981). Beyond culture. New York: Doubleday.

Hofstede, G. (1980/1984). Culture's Consequences: International Differences in Work Related Attitudes. Beverly Hills, CA: Sage Publications.

Hofstede, G. (1991). Cultures and Organizations. New York: McGraw Hill.

Holsti, O. (1969). Content Analysis for the Social Sciences and Humanities. Reading, MA: Addison-Wesley.

Ju-Pak, K. H. (1999). Content Dimensions of Web Advertising: A Cross-national Comparison. International Journal of Advertising, 18 (2), 207-231.

Kabasakal, H., Asugman, G. \& Develioglu, K. (2006). The Role of employee preferences and organizational culture in explaining e-commerce orientations. International Journal of Human Resource Management, 17(3), 464-483.

Okazaki, S. (2004). Does Culture Matter?: Identifying Cross-national Dimensions in Japanese Multinationals' Product-based Websites. Electronic Markets, 14(1), 58-69.

Singh, N., Hongxin, X. \& Xiaorui, H. (2003). Cultural Adaptation on the Web: A study of American Companies' Domestic and Chinese Websites. Journal of Global Information Management, 11(3), 63-80.

Simon, S. J. (1999). A Cross-Cultural Analysis of Web Site Design: An Empirical Study of Global Web Users. Paper presented in Seventh Cross-Cultural Consumer Business Studies research Conference. Cancun, Mexico.

Ward, J. H. (1963). Hierarchical grouping to optimize an objective function. Journal of American Statistical Association, 58(301), 236-244.

Zhao, W., Massey, B., Murphy, J. \& Fang, L. (2003). Cultural Dimensions of Website Design and Content. Prometheus, 21(1), 75-84.

Zimmer, M. R. \& Golden, L. L. (1988). Impressions of Retail Stores: A Content Analysis of Consumer Images. Journal of Retailing, 64(3), 265-293. 
Table 1. Website Features

\begin{tabular}{|l|l|}
\hline $\begin{array}{l}\text { Uncertainty Avoidance } \\
\text { Site map } \\
\text { Search } \\
\text { Conventional approach } \\
\text { Company history }\end{array}$ & Individualism - Collectivism \\
& Family / Group theme \\
Ge" approach \\
Group activities \\
\hline $\begin{array}{l}\text { Masculinity - Femininity } \\
\text { Annual reports } \\
\text { Success stories } \\
\text { Clear gender roles }\end{array}$ & $\begin{array}{l}\text { High - Low Context } \\
\text { Animation } \\
\text { High proportion of pictures } \\
\text { Undetailed information } \\
\text { Multiple sidebars }\end{array}$ \\
\hline
\end{tabular}

Table 2. Frequency of Items under Cultural Value Dimensions

\begin{tabular}{|c|c|c|c|c|}
\hline & $\underline{\text { TURKEY }}$ & $\underline{\text { USA }}$ & $\underline{\text { F-statistic }}$ & \\
\hline \multicolumn{5}{|l|}{ Individualism-Collectivism } \\
\hline 1.Family / Group theme & $30 \%$ & $14 \%$ & 3.34 & $*$ \\
\hline 2."We" approach & $29 \%$ & $14 \%$ & 3.33 & $*$ \\
\hline 3.Group Activities & $11 \%$ & $9 \%$ & 0.12 & \\
\hline \multicolumn{5}{|l|}{ Uncertainty Avoidance } \\
\hline 1.Site map & $57 \%$ & $80 \%$ & 5.44 & ${ }^{* *}$ \\
\hline 2.Search & $61 \%$ & $100 \%$ & 27.07 & **** \\
\hline 3.Conventional approach & $30 \%$ & $30 \%$ & 0 & \\
\hline 4.Company history & $59 \%$ & $84 \%$ & 7.16 & ${ }^{* * *}$ \\
\hline \multicolumn{5}{|l|}{ Masculinity - Femininity } \\
\hline 1.Annual reports & $9 \%$ & $95 \%$ & 254.48 & *** \\
\hline 2.Success stories & $11 \%$ & $70 \%$ & 48.61 & ${ }^{* * *}$ \\
\hline 3.Clear gender roles & $5 \%$ & $0 \%$ & 2.05 & \\
\hline \multicolumn{5}{|l|}{ High - Low Context } \\
\hline 1.Animation & $48 \%$ & $41 \%$ & 0.41 & \\
\hline 2.High proportion of pictures & $80 \%$ & $16 \%$ & 58.73 & **** \\
\hline 3.Undetailed information & $93 \%$ & $39 \%$ & 42.56 & ${ }^{* * *}$ \\
\hline 4.Multiple sidebars & $100 \%$ & $89 \%$ & 5.51 & $* *$ \\
\hline
\end{tabular}

Note: ${ }^{* *}$ Significant at $1 \%,{ }^{* *}$ significant at $5 \%,{ }^{*}$ significant at $10 \%$.

Table 3. ANOVA Results for Four Cultural Dimensions

\begin{tabular}{|lcccll|}
\hline Dimension & TURKEY & $\underline{\text { USA }}$ & $\underline{\text { F-statistic }}$ & \\
Individualism-Collectivism & $55 \%$ & $8 \%$ & 186.56 & $* * *$ \\
Uncertainty Avoidance & $52 \%$ & $73 \%$ & 18.67 & $* * *$ \\
Masculinity - Femininity & $13 \%$ & $23 \%$ & 4.35 & $* *$ \\
High - Low Context & $63 \%$ & $44 \%$ & 16.75 & $* * *$ \\
\hline
\end{tabular}

Note: ${ }^{* * *}$ Significant at $1 \%,{ }^{* *}$ significant at $5 \%,{ }^{*}$ significant at $10 \%$. 
Table 4. ANOVA Results for Cluster Analysis

\begin{tabular}{|lcccccc|}
\hline & $\begin{array}{c}\text { Cluster } \\
\text { Mean Square }\end{array}$ & df & $\begin{array}{c}\text { Error } \\
\text { Mean Square }\end{array}$ & df & F-statistic & \\
Individualism-Collectivism & & & & & & \\
1.Family / Group theme & .704 & 1 & .165 & 86 & 4.266 & $* *$ \\
2."We" approach & .392 & 1 & .169 & 86 & 2.321 & \\
3.Group Activities & .004 & 1 & .094 & 86 & .042 & \\
Uncertainty Avoidance & & & & & & \\
1.Site map & 1.447 & 1 & .205 & 86 & 7.053 & $* * *$ \\
2.Search & 3.597 & 1 & .118 & 86 & 30.569 & $* * *$ \\
3.Conventional approach & .008 & 1 & .213 & 86 & .036 & \\
4.Company history & 2.276 & 1 & .182 & 86 & 12.527 & $* * *$ \\
Masculinity - Femininity & & & & & & \\
1.Annual reports & 16.364 & 1 & .065 & 86 & 251.758 & $* * *$ \\
2.Success stories & 6.759 & 1 & .169 & 86 & 40.052 & $* * *$ \\
3.Clear gender roles & .050 & 1 & .022 & 86 & 2.248 & \\
High - Low Context & & & & & & \\
1.Animation & .259 & 1 & .249 & 86 & 1.040 & \\
2.High proportion of pictures & 8.870 & 1 & .152 & 86 & 58.296 & $* * *$ \\
3.Undetailed information & 8.526 & 1 & .131 & 86 & 65.200 & $* * *$ \\
4.Multiple sidebars & .311 & 1 & .051 & 86 & 6.075 & $* *$ \\
\hline
\end{tabular}

Note: ${ }^{* * *}$ Significant at $1 \%,{ }^{* *}$ significant at $5 \%,{ }^{*}$ significant at $10 \%$. 